\title{
An Investigation of the Cooperative Learning Process of Students with Hearing Loss in the Social Studies Course
}

\author{
Elif Akay ${ }^{1, *}$ \\ ${ }^{1}$ Faculty of Education, Department of Special Education Faculty Member, Anadolu University, Eskişehir, Turkey \\ *Correspondence: Faculty of Education, Department of Special Education Faculty Member, Anadolu University, \\ Eskisehir, Turkey. Tel: 90-222-335-0580. E-mail: elifakay@anadolu.edu.tr. https://orcid.org/0000-0002-7349-6217
}

Received: August 24, 2020

Accepted: November 9, 2020 Online Published: December 20, 2020

doi:10.5430/wje.v10n6p84

URL: https://doi.org/10.5430/wje.v10n6p84

\begin{abstract}
The Social Studies course, as part of the curriculum starting with primary school, aims to improve the social adaptation skills of students. Cooperative learning reinforces these skills by providing students with active involvement opportunities to set common goals in small heterogeneous groups. This case study investigates the implementation of the cooperative learning model in the Social Studies course with $4^{\text {th }}$ grade students with hearing loss. The data were collected via video recordings of the lessons, voice recordings of the validity and reliability committee, documents, the researcher's journal, and the process-products. Per the outcomes of this study, it is safe to state that the cooperative learning model contributes to debating skills on the Social Studies concepts as well as knowledge transfer, reasoning, and positive interdependence skills of students with hearing loss who receive an education based on the auditory-oral approach.
\end{abstract}

Keywords: auditory-oral approach, cooperative learning, social studies, student with hearing loss, teaching strategies

\section{Introduction}

The Social Studies course is based on group work that prepares students for social life by developing interpersonal relationships, democratic values, and social processes that require collaboration (Zarrillo, 2012). The course encompasses various activities such as debates, watching films, examining documents/objects that help students learn specific concepts through group discussions (Obenchain \& Morris, 2011). The importance of language development and acquisition of new experiences has been repeatedly emphasized in the process of concept learning (Neuman, Newman \& Dwyer, 2011). Students with hearing loss (SHL), therefore, need active participation opportunities in the educational environment where they can improve oral language skills from the early ages onward so that they can achieve concept development (Pimperton \& Kennedy, 2012). The auditory-oral approach is used to facilitate the active participation of SHL in the educational process, where they can work in small groups using their oral language skills. The auditory-oral approach is a thematic application that supports communication skills and enables the acquisition of experience through doing/living (Clark, 2006). Another practice that promotes active participation is the cooperative learning model (CLM). CLM is defined as the collaboration of students towards a common goal in order to access information, perform a task, or solve a problem (Johnson \& Johnson, 2017). CLM is the kind of teamwork in which students' success improve collectively. This kind of collaboration, like the auditory-oral approach, facilitates the transfer of information to long-term memory by improving skills to access, structure, and present information (Klinger, Vaughn \& Schumm, 1998; Slavin, 1983).

This study investigates the application of the cooperative learning model in the Social Studies course in a teaching-learning environment where SHL receive an auditory-oral approach-based education. It has been demonstrated that quality group work in CLM depends on (a) effective planning, (b) group work with a common goal, (c) collaboration with students in the group, and (d) the creation of a specific product as a result of the group work (Slavin, 2015). In order to achieve effective planning in CLM, it is essential to set realistic goals, choose suitable materials, and form heterogeneous groups. While the course materials help materialize the concepts, heterogeneous groups discard individual competition, reinforce positive interdependence, and strengthen the mutual trust (Zarrillo, 2012). Group work with a common goal provides opportunities to debate concepts, use information in different contexts, and reason (Johnson \& Johnson, 2017). The process of collaboration in CLM reinforces the 
fulfillment of responsibilities and positive interdependence. This increases student success through the activation of cognitive mechanisms (Dillenbourg, 1999). CLM also enables students to create their own products by adopting collaboration in group work with a common goal (Zarrillo, 2012). Evidently, CLM rests on shared features with the Social Studies course objectives and the auditory-oral approach. These shared features, such as integrating existing knowledge with the new information, reasoning, positive interdependence, improvement of debating skills, and the follow-up activities offer critical opportunities in the education of SHL (Clark, 2006).

Numerous international studies in the field of Social Studies involving children without hearing loss also point out that CLM increases motivation, success, and retention of knowledge to a larger extent compared to larger group works (e.g., Adams, 2013; Scheuerell, 2010). Similarly, national studies on Social Studies involving students without hearing loss display a higher efficiency in research skills, learning concepts, and school success in CLM compared to traditional methods (Korkmaz, Toklucu, \& Tay, 2016; Kus \& Karatekin, 2009).

It is observed that several international studies on CLM involving SHL focus on social skills in an inclusive educational environment (e.g., Antia, Kreimeyer, \& Eldredge, 1994; Ducharme \& Holborn, 1997). Studies investigating academic development have ascertained that SHL in inclusive educational environments perform better under CLM than they do individually and that they receive support from other group members to make sense of the information (Johnson \& Johnson, 1985; Kluwin, Stinson, \& Colarossi, 2002; Reilly, Nguyen \& Khanh, 2004). It is also important that the students are genuine members of the class to reap the expected benefits of CLM practices (Antia, Stinson, \& Gaustad, 2002). It has been noted that the oral language skills of the SHL are a determinant in the process (Stinson \& Liu, 1999). There is just one study on the development of social skills of SHL using CLM in national literature (Avcioglu, 2001). This study involves 9 students aged between 9 and 12 in a primary school special education class. The study reveals that CLM is influential in the initiation and maintenance of inter-group interaction by SHL while playing with their hearing peers and the generalization of these skills.

There are few studies in international literature involving CLM use in the Social Studies course with SHL (Gaustad, 1999; Miller, 1995). These studies point out that small group work within the CLM framework reinforces interaction among peers and gives the SHL a greater chance to participate in the lessons. They also express the need to provide students with wider opportunities to discuss concepts. In national literature, however, there are no studies concerning the use of CLM in the Social Studies course with SHL. Although there are CLM studies that focus on the development of academic success in the international literature (Gaustad, 1999; Johnson \& Johnson, 1985; Kluwin, Stinson \& Colarossi, 2002; Miller, 1995; Reilly, Nguyen, \& Khanh, 2004), there are no cases where the CLM process involving SHL has been investigated in the Social Studies course.

With their growing use in recent years, cochlear implants, which play a prominent role in earlier interventions, make it easier for SHL to receive an education based on the auditory-oral approach (Boons et al., 2013). This study has been carried out in the Education and Research Center for Hearing-Impaired Children (ICEM) at Anadolu University. SHL experience latency in their academic skills because of the latency in their language skills. This does not only affect the students' oral language skills but also play a defining role in their communication with their peers (Stinson \& Liu, 1999). Moreover, their condition limits their development in the Social Studies, literacy (Karasu, Girgin \& Gurgur, 2015), and Mathematics courses (Leton, Wahyudin, \& Dosinaeng, 2019), all of which require academic skills. Therefore, it is important that SHL are taught how to use learning strategies. The Social Studies Course covers fundamental strategies that improve skills such as using resources, reasoning, comparing and contrasting, perceiving time and space, and learning new vocabulary (Levstik \& Barton, 2001). It is observed that rich material support, simplified explanations, and research samples that provide experience are required to equip SHL with these strategies.

The Social Studies program prepared for hearing children can be used in the education of SHL by applying necessary adaptations on informative texts and offering a variety of materials. In this study, the Primary $4^{\text {th }}$ Grade Social Studies coursebook, prepared for the 2017-2018 academic year by the Ministry of National Education, has been used with the necessary adaptations and material support. Findings could contribute to instructional practices and program applications for SHL. In addition, they may constitute examples of the instructional environment designed for the use of academic information. Besides, this study could potentially guide teachers and researchers by defining the CLM application process and exposing the needs of SHL in this kind of an application.

Overall, this study aims to investigate the CLM applications in the Social Studies course for $4^{\text {th }}$-grade students with hearing loss who receive an education based on the auditory-oral approach. In line with this purpose, the researcher attempted to answer the questions: (a) which activities have been carried out in the Social Studies course and (b) how was CLM carried out in the Social Studies course? 


\section{Method}

This study used a holistic single case study approach to investigate the cooperative learning status of $4^{\text {th }}$ grade SHL in the Social Studies course for the entire duration of the term and an explanatory case study approach to describe how CLM takes place. A case study is an in-depth analysis of a subject or a situation in its original context staying true to the actual process (Yin, 2014).

\subsection{Educational Environment}

This study was conducted at ICEM, founded in 1979 at Anadolu University, to provide an auditory-oral approach-based education to children with hearing loss. ICEM provides early diagnosis, provision of assistive devices, and encouragement for cochlear implant applications, along with family education, pre-school, primary school, and secondary school education. The center also supports inclusive classrooms.

The research group has been seated in the classroom in a way that would allow them to see one another as well as their teacher at all times. On the classroom walls were notice boards where process products were on display.

\subsection{Participants}

The participants in the study were eight $4^{\text {th }}$ grade SHL at ICEM, and the researcher, who is a teacher for hearing-impaired children. The demographic, audiological, and educational background of the students is presented in Table 1. Students' names have been changed to observe ethical principles.

Table 1. Students' Demographical, Audiological and Educational Backgrounds

\begin{tabular}{|c|c|c|c|c|c|c|c|}
\hline \multirow[t]{2}{*}{ Student } & \multirow[t]{2}{*}{$\begin{array}{c}\text { Chronological } \\
\text { Age }\end{array}$} & \multicolumn{2}{|c|}{ Hearing Aid Use } & \multirow{2}{*}{$\begin{array}{c}\begin{array}{c}\text { Hearing } \\
\text { sensation } \\
\text { level } \\
(\mathrm{dBHL})\end{array} \\
\text { Left }\end{array}$} & \multirow[t]{2}{*}{$\begin{array}{c}\text { Age of provision } \\
\text { of an assistive } \\
\text { device }\end{array}$} & \multirow[t]{2}{*}{$\begin{array}{l}\text { Cochlear } \\
\text { Implant Age }\end{array}$} & \multirow[t]{2}{*}{$\begin{array}{c}\text { Enrollment age } \\
\text { at ICEM }\end{array}$} \\
\hline & & Left & Right & & & & \\
\hline Tulin & $9 ; 8$ & $\mathrm{BA}^{*}$ & $\mathrm{CI}^{* *}$ & 115 & $0 ; 8$ & $1: 5$ & $3: 2$ \\
\hline Ibrahim & $9 ; 5$ & BA & $\mathrm{CI}$ & 121 & $1 ; 7$ & $2: 3$ & $2: 11$ \\
\hline Ufuk & $9 ; 5$ & BA & $\mathrm{CI}$ & 72 & $2 ; 1$ & $2: 8$ & $2: 9$ \\
\hline Rutkay & $9 ; 10$ & BA & CI & 90 & $2 ; 8$ & $3: 7$ & $3: 9$ \\
\hline Mehmet & $9 ; 5$ & BA & BA & 76 & $4 ; 7$ & - & $4: 11$ \\
\hline Cengiz & $9 ; 6$ & BA & CI & 106 & $0 ; 6$ & $1: 11$ & $3: 11$ \\
\hline Tarkan & $9 ; 10$ & BA & $\mathrm{CI}$ & 94 & $2 ; 11$ & $3: 4$ & $4: 4$ \\
\hline Murat & $9 ; 6$ & BA & $\mathrm{CI}$ & 96 & $1 ; 10$ & $2: 6$ & $3: 0$ \\
\hline
\end{tabular}

*BA: Behind-the-ear aid

**CI: Cochlear Implant

As shown in Table 1, four students have profound hearing loss, whereas one of them has severe, and the remaining three have moderately severe hearing loss. The students started using hearing aids between the ages of 8 months and 2 years and 11 months. According to the information obtained from the audiology and psychology clinics of the center, the students were not diagnosed with any additional disabilities. All students received family education. They enrolled in formal education at ICEM between 2 years and 9 months and 4 years and 11 months. In accordance with the ethical principles, the families were informed about the study and gave their written consent in advance.

\subsection{Data Source and Procedures}

The variety of data collection tools in case studies is vital in terms of validity and reliability (Yin, 2014). The data in this study was collected through video and audio recordings, documents, the researcher's log, and process-products. The data was collected in the second semester of the 2017-2018 academic year between 26.02.2018 and 20.04.2018 in the Social Studies lessons with CLM practices.

\subsection{Data Analysis}

Video recordings of 33 Social Studies lessons and eight validity and reliability meetings have been documented. Recurring themes have been analyzed descriptively and presented within the application stages of CLM under the headings of (a) planning, (b) collaboration, (c) group work, and (d) creating a product. 


\subsection{Validity and Reliability}

Scripts of the video recordings of the lessons and the audio recordings, the variety of data collection tools, themes, lesson plans, and the researcher's log have been checked by the reliability and validity committee both during and after the study.

\section{Results}

This section proposes answers to the questions (a) what kind of activities has been carried out in the Social Studies course and (b) how the CLM applications are put into actual practice with the auditory-oral approach.

\subsection{What Kind of Activities Has Been Carried out in the Social Studies Course?}

33 Social Studies lessons were held in the scope of this study. Findings concerning the activities carried out in these lessons are presented in Table 2.

Table 2. The Activities Carried out in the Social Studies Course

\begin{tabular}{|c|c|c|c|c|c|}
\hline Unit & Date & Video/Duration & Subject & Activities & Purpose \\
\hline \multirow{36}{*}{$\begin{array}{c}\text { Science, } \\
\text { Technology } \\
\text { and the Society }\end{array}$} & 26.02 .2018 & V1/1h09'50', & $\begin{array}{l}\text { Technological Devices Around } \\
\text { Us }\end{array}$ & $\begin{array}{l}\text { Watching an instructional video } \\
\text { Building a model tablet }\end{array}$ & $\begin{array}{l}\text { Discussion } \\
\text { Comparison }\end{array}$ \\
\hline & 27.02 .2018 & $\mathrm{~V} 2 / 1 \mathrm{~h} 22^{\prime} 17^{\prime}$, & Life Before the Development & Watching an instructional video & Discussion \\
\hline & & & of Technology & Building a model & Comparison \\
\hline & 28.02 .2018 & $\mathrm{~V} 3 / 1 \mathrm{~h} 21^{\prime} 49^{\prime}$, & Developments in The Field of & Preparing timeline & Perceiving Time \\
\hline & & & $\begin{array}{l}\text { Transportation, Health and } \\
\text { Education }\end{array}$ & Preparing posters & Categorizing \\
\hline & 01.03 .2018 & V4/1h11'48', & Historical Development of The & Examining an object & Association \\
\hline & & & Timepiece & Preparing timeline & Perceiving Time \\
\hline & & & & Building a model & Comparison \\
\hline & 02.03 .2018 & V5/1h21'12', & Historical Development of The & Watching an instructional video & Discussion \\
\hline & & & Wheel & Preparing timeline & Perceiving Time \\
\hline & & & & Building a model & Comparison \\
\hline & 05.03 .2018 & V6/1h09'25', & Historical Development of The & Watching a documentary & Discussion \\
\hline & & & Wheel & Preparing poster & Categorizing \\
\hline & 06.03 .2018 & V7/1h26’39', & The Invention of The & Watching a documentary & Discussion \\
\hline & & & Telephone & Preparing timeline & Perceiving Time \\
\hline & & & & Preparing of posters & Categorizing \\
\hline & 07.03 .2018 & V8/1h20'33', & The Invention of The Light & Watching a documentary & Discussion \\
\hline & & & Bulb & Examination an object & Association \\
\hline & & & & Preparing a timeline & Perceiving Time \\
\hline & & & & Preparing posters & Categorizing \\
\hline & 08.03 .2018 & V9/1h30’02', & The Invention of The Aeroplan & Watching a documentary, & Discussion \\
\hline & & & & Preparing timeline & Perceiving Time \\
\hline & & & & Building a model & Comparison \\
\hline & 09.03 .2018 & $\mathrm{~V} 10 / 1 \mathrm{~h} 27^{\prime} 53^{\prime}$ & A Documentary of Inventions & Watching a documentary & Discussion \\
\hline & & & & Preparing a table & Categorizing \\
\hline & 12.03 .2018 & V11/1h06'18', & Means of Communication & Watching a documentary & Discussion \\
\hline & & & & Preparing a poster & Categorizing \\
\hline & 13.03.2018 & V12/1h23'11'” & Historical Development of & Watching an instructional video & Discussion \\
\hline & & & Computers and The Internet & Examining an object, & Association \\
\hline & & & & Preparing a timeline & Perceiving Time \\
\hline & 14.03 .2018 & V13/1h19’36" & Let's Design & Examination an object & Association \\
\hline & & & & Preparing a model & Comparison \\
\hline & 15.03 .2018 & V14/1h23’20', & Benefits of Technology & Watching an instructional video & Discussion \\
\hline & & & & Preparing a poster & Categorizing \\
\hline & 16.03.2018 & V15/1h22'56’' & Disadvantages of Technology & Watching a movie & Discussion \\
\hline & & & & & Association \\
\hline
\end{tabular}




\begin{tabular}{|c|c|c|c|c|c|}
\hline \multirow{3}{*}{$\begin{array}{c}\text { Production, } \\
\text { Distribution } \\
\text { and }\end{array}$} & 19.03.2018 & V16/1h16'33', & Needs or Wants? & Watching an instructional video & Discussion \\
\hline & & & & Preparing a poster & Categorizing \\
\hline & 20.03.2018 & V17/1h11'18', & Basic and Social Needs & Watching an instructional video & Discussion \\
\hline \multirow[t]{16}{*}{ Consumption } & & & & Preparing a poster & Categorizing \\
\hline & 21.03 .2018 & V18/1h24'15', & Production Activities & Watching an instructional video & Discussion \\
\hline & & & & Building a model & Comparison \\
\hline & 22.03 .2018 & V19/1h23'16", & I Choose A Profession & Watching an instructional video & Discussion \\
\hline & & & & Preparing a poster & Categorizing \\
\hline & 23.03 .2018 & V20/1h26'15', & Characteristics of Professions & Watching an instructional video & Discussion \\
\hline & & & & Preparing a poster & Categorizing \\
\hline & 26.03.2018 & V21/1h07'42'” & Features of Products We Buy & Watching an instructional video & Discussion \\
\hline & & & & Examining an object & Association \\
\hline & & & & Building a model & Comparison \\
\hline & 27.03 .2018 & V22/1h34'56"' & Budget in Shopping & Watching an instructional video & Discussion \\
\hline & & & & Examining a document & Research \\
\hline & & & & Preparing a table & Association \\
\hline & 28.03.2018 & V23/1h23'12’” & My Rights and & Watching an instructional video & Discussion \\
\hline & & & Responsibilities as a Customer & Examining a document & Research \\
\hline & 30.03 .2018 & V24/1h05'11", & Saving and Squandering & $\begin{array}{l}\text { Watching an instructional video } \\
\text { Preparing posters }\end{array}$ & $\begin{array}{l}\text { Discussion } \\
\text { Categorizing }\end{array}$ \\
\hline Active & 02.04 .2018 & $\mathrm{~V} 25 / 1 \mathrm{~h} 05{ }^{\prime} 21{ }^{\prime \prime}$ & What are Children's Rights? & Examination document & Research \\
\hline \multirow[t]{15}{*}{ Citizenship } & 03.04 .2018 & V26/1h01'38', & I Have the Right to be a Child & Preparing a poster & Categorizing \\
\hline & 04.04 .2018 & $\mathrm{~V} 27 / 1 \mathrm{~h} 16^{\prime} 47^{\prime \prime}$ & $\begin{array}{l}\text { Our Responsibilities as } \\
\text { Children }\end{array}$ & Discussion of responsibilities & Discussion \\
\hline & 09.04 .2018 & V28/1h10’34', & I Want to Join the Children's & Watching an instructional video & Discussion \\
\hline & & & Clubs & Preparing a poster & Categorizing \\
\hline & 10.04 .2018 & V29/1h17'54', & Coding Club & Playing digital coding game & Association \\
\hline & & & & Preparing a poster & Categorizing \\
\hline & 11.04 .2018 & V30/1h21'44', & Objectives of the & Examining web page & Research \\
\hline & & & $\begin{array}{l}\text { Non-Governmental } \\
\text { Organizations }\end{array}$ & Preparing a poster & Categorizing \\
\hline & 12.04 .2018 & V31/1h27'15', & Characteristics of & & Research \\
\hline & & & $\begin{array}{l}\text { Non-Governmental } \\
\text { Organizations }\end{array}$ & Building a model & Comparison \\
\hline & 13.04 .2018 & $\mathrm{~V} 32 / 1 \mathrm{~h} 26^{\prime} 02^{\prime \prime}$ & Examples to & & Research \\
\hline & & & Non-Governmental & $\begin{array}{l}\text { Examining web page, } \\
\text { Building a model }\end{array}$ & Comparison \\
\hline & & & Organizations & & \\
\hline & 17.04 .2018 & V33/1h14'08', & Governing of Our Country & Examining web page & Research \\
\hline & & & & Preparing a poster & Comparison \\
\hline
\end{tabular}

The study encompasses 33 activities within three units titled "Science, Technology and Society," "Production, Distribution and Consumption," and "Active Citizenship" covered during the second term of the Social Studies course of the Ministry of National Education. Students have been encouraged to participate in classroom debates using the Social Studies course content through explanations, question-and-answer sessions, and problem-solving techniques.

It is important to use supplementary materials to facilitate the learning of Social Studies concepts for SHL. A variety of such materials have been used in this study in each unit and activity. One such material is Vitamin Interaktif Egitim videos (http://www.vitaminegitim.com/). This material is originally prepared for hearing students at different levels of the educational program of the Ministry of National Education. It contains animations on course content and unit tests. A total of 15 instructional videos have been used in this study on the topics of technological products around us, transportation, communication, development of computers, uses of technology, basic and social needs, production activities, professions, features of products, budget, consumer rights, saving and squandering, and clubs. Available scenes to attain goals and discuss the concepts have been determined in advance by watching these videos before the lessons. The fact that the instructional videos were related to the course content of the Social Studies course 
for the $4^{\text {th }}$ grade provided SHL with the opportunity to discuss the concepts involved. For instance, while working on the budget in the "Budget in Shopping" component of the course, students watched the video on incomes and expenditures in addition to examining a real electricity bill and real banknotes in the classroom as realia.

The study relied substantially on documentaries and films. These materials helped students to visualize and materialize the characteristic features of the events experienced in the past. Documentaries and films have been used in a similar way to the instructional videos. A total of five documentaries were used in the course. The Historical Development of the Wheel, The Invention of the Light Bulb, The Invention of the Telephone, and The Invention of the Airplane, 1001 Inventions and The Library of Secrets were broadcast on the social network YouTube. For instance, through the documentary titled "The Invention of the Airplane," the students were given the experience to observe that the Wright brothers were two men, that the airplane they invented was different from the ones we know today, and that they built the first motorized airplane (V9, 45'30"). While covering the chapter on "Science, Technology and the Society," the impact of inventors and creativity on technology has been demonstrated through the movie "Back to the Future 1". Students stated that the inventor in the movie invented a time machine. Ibrahim has said that he would like to go to the last day of the Earth (V15, 13'07'). To ensure that the SHL understood the theme in the instructional videos, documentaries and movies, the teacher paused the video at times and initiated a classroom debate.

Authentic documents and objects have also been used in the study. These helped students integrate and materialize the connection between the subject matter and real-life by offering hard evidence concerning the concepts. The teacher chose these materials before the lessons. Documents examined during the study include the Declaration of the Rights of the Child, a bill of warranty, an electricity bill, and savings posters. The classroom discussions within the chapter's coverage on "Science, Technology and the Society" have been carried out using realia such as a computer, a mobile phone, a clock, a lightbulb, and packed products (milk carton). For instance, in the "Saving and Squandering" chapter, failing to preserve freshwater sources has been suggested as a reason for draught. The teacher used a flier on the Internet and its motto as a visual for the subject matter. Consequently, Mehmet arrived at the conclusion that "The flier is used to inform people about what they must do" (V24, 15'08").

Students also drew up a timeline in the study. This timeline helped show students the interval between these events and the present. The timeline was laid down as an empty chart originally. Each invention studied in the "Development of Technology" chapter was placed on the timeline. This activity enabled students to visualize when these inventions were made, and which one came first. In the chapter titled "The Invention of The Telephone," students placed a photograph of Alexander Graham Bell and their notes about the invention of the telephone on the corresponding section of the timeline (V7, 27'51').

Follow-up activities were carried out after the classroom discussions on the subject matter and the concepts of the Social Studies lessons. A follow-up activity is a subsequent lesson where the students collaboratively create a product related to the subject matter. These activities reinforce the retention of the information and refresh the experiences acquired during the lessons on the topics and concepts discussed in the classroom (Remmen \& Frøyland, 2015). Students use stationery products and scrap materials in the classroom to create dictionaries, booklets, models, and posters in the process. They also prepare and picture task cards with topic-related information on them. Task cards provide the students with a second opportunity to revise and visualize in written form the information discussed in the classroom (Johnson, Wardlow \& Franklin, 1997). Individual differences among students should be considered during the preparation of these task cards. Objects or places discussed in the classroom were turned into 3D models, and students drew pictures of the events discussed in the classroom on large pieces of paper as posters. Students' notes at the end of the lesson were written down with their teacher's guidance and added to the final products. Throughout the study students produced nine models - of a tablet, a washing machine, an hourglass, a horse cart, a wheel, an airplane, an olive oil mill, a milk carton, and mobile education trucks; and 13 posters - on the TV, the telephone, the computer, The Development Of The Wheel, The Development Of The Telephone, Kinds Of Lightbulbs, Means Of Communication, Technological Products, Our Wants and Our Needs, Professions, Children's Rights, and National and Local Governments. These were initially put on display on the classroom noticeboards and activity corners and then in the school corridors. Follow-up activities facilitated students' group work and collaboration towards a common goal. Students not also managed to integrate the new information acquired in these activities with their previous knowledge but also succeeded in oral and written use of the concepts discussed in the Social Studies lessons through their description of the activities.

\subsection{How Was CLM Carried out in the Social Studies Lessons?}

The CLM process carried out with SHL in the Social Studies course is presented in Figure 1. 


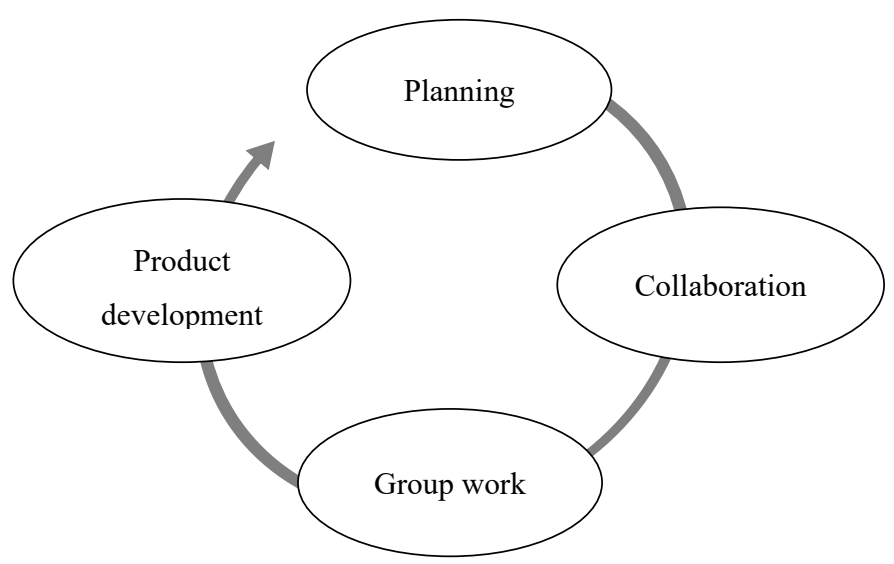

Figure 1. The CLM Process

CLM starts with the teacher planning the lesson. The lessons are designed to include activities that can be carried out as a group. Classroom materials are prepared. Students share information through collaboration, work as a group to achieve common goals, and come up with a collective product at the end of the process. Findings concerning the CLM applications are shown below.

\subsubsection{Planning}

Effective planning in CLM requires setting realistic goals, forming heterogeneous groups, and preparing suitable materials. The goals were selected with an eye to the targeted achievements in the $4^{\text {th }}$ grade of national education and adapted to the needs of SHL. For instance, the achievement objective for the primary $4^{\text {th }}$ grade Social Studies lesson titled "Developments in the Fields of Transportation, Health and Education," dated 28.02.2018, is stated as "SS.4.4.1. (Students) categorize the technological products around them according to their field of use," in the curriculum. This achievement was redesigned for SHL as follows:

(Students can)

- exemplify the technological products around them.

- explain how technological products in transportation save time.

- predict that the technological products in Health Care make it easier to treat diseases.

- relate that use of technology in education facilitates access to information.

- conclude that a common characteristic of technological products is that they make our lives easier.

- categorize the examples of technological products under transportation, health, and education titles.

In order for the participants to attain the planned objectives, utmost attention was paid to set goals that would ensure that the participating students could use already existing knowledge to reach the concepts that they were expected to learn, that they could establish connections, and compare and contrast the ideas.

CLM aims to enable students to learn from one another by forming heterogeneous groups. All $4^{\text {th }}$ grade students participated in the study. There were 8 students in the class. The groups displayed a natural heterogeneity due to the individual differences between the students in terms of knowledge, experience, and communication skills.

The selection of suitable materials is also critical in CLM. In this study, materials were chosen specifically to enable SHL to get involved in classroom discussions using the concepts learned in the Social Studies course. For instance, in the chapter on "The Historical Development of the Wheel," they were presented with visuals of both a wooden and a stone wheel, with the expectation that they would compare and contrast the wheels according to their size, mass, and ease of production.

\subsubsection{Collaboration}

CLM encourages students to collaborate and fulfill individual responsibilities and work in positive interdependence both in the lessons and the follow-up activities. Students' participation in collaboration under CLM is presented in Sample 1. 


\section{Sample 1}

At the end of the "Production Activities" chapter, the students decided to build an olive oil mill to demonstrate the stages of olive liquefaction. Before they started building the model, they examined the parts of the mechanism. Since the instrument consisted of several parts, they decided to share the work. Mehmet said that he would build the part where the olives are washed, Ufuk took the part where the olives are crushed, and Ibrahim volunteered to make the part where they are dried. Cengiz and Tulin assumed the attachment of the toothpicks to the cylindrical boxes to construct one of the gearwheels of the mechanism. Murat said that he wanted to build the pipes where the pulp was separated from the oil (V18, 47'57').

As seen in Sample 1, students assumed individual responsibilities by sharing the work before starting the activity. Then they were asked to explain which part of the work they would perform.

CLM facilitates positive interdependence among students. This positive interdependence in the lessons enabled students to learn Social Studies concepts from their peers and created a learning environment enriched with active participation. Accordingly, students were given a chance to determine the activity that they would carry out and express their thoughts about it at the start, as exemplified in Sample 2.

\section{Sample 2}

In the chapter titled "Technological Products around Us," when Rutkay talked about unmanned aerial vehicles, Ibrahim interfered and said they were called 'drones.' When Cengiz asked what 'drone' meant, Rutkay said that they were airplanes that didn't carry people, that they were operated by remote control and that they could not be detected by radars. (V1, 38'57').

Sample 2 demonstrates that interaction among peers facilitates learning. Individual differences between students sometimes make it difficult for them to understand the subject matter and participate in group activities. Positive interdependence reinforced peer support without the need for the teacher to intervene.

\subsubsection{Group Work}

CLM is a process in which students reason, discuss and relate existing knowledge with new information. Throughout the process, students are asked questions and offered explanations to encourage them to participate in classroom discussions. An instance where students related existing knowledge with new information can be seen in Sample 3.

\section{Sample 3}

Students were shown a photo of the telegraph in the chapter titled "Means of Communication." They were asked how communication was carried out using this device. Mehmet came up with the explanation that the telegraph has an alphabet consisting of short and long taps on the device. Ufuk, taking the lead by Mehmet, reminded his friends of the scene where the telegraph was used in the film "Taş Mektep" watched by the students as part of the chapter on "National Struggle" (V10, 12'55").

As seen in Sample 3, in order to enable students to relate existing knowledge with the new information, they were initially presented with the opportunity to talk about what they know about the subject at hand, which enabled them to express their opinions on the issue regarding their peers'. CLM also reinforces students' ability to establish causal relationships through reasoning as a group, exemplified in Sample 4.

\section{Sample 4}

In the chapter on the "Invention of the Airplane," the students were asked why people could travel only short distances with wings. Tarkan answered the question by saying that one would also need propellers. Rutkay listened to Tarkan and added that people are too heavy. And Cengiz contributed by saying that the wings would be useless when they got wet in the rain (V9, 14'00').

As seen in Sample 4, students were asked specific questions that would require them to use their past experiences, establish connections between events, and use their problem-solving skills to use reasoning.

\subsubsection{Creating a Product}

CLM creates an environment where students create a product as a result of collaborative work. It also offers the students the opportunity to put their observations into words. This process improves the students' ability to access, structure, and present the information, enabling the transfer of information to long-term memory. Creating a product of CLM has been carried out over the follow-up activities in this study. Products developed in the follow-up activities were first put on display in the classroom noticeboards, and then they were exhibited in the school corridors. Sample 5 exemplifies cases that led to these findings. 


\section{Sample 5}

In the chapter on "The Technological Products around Us," students built a model of a device of their choice. Ufuk, Mehmet, Tulin and Rutkay opted for building a model tablet. They decided that it should be a three-dimensional model. They examined the boxes available in the classroom to make a model tablet. Rutkay said that the boxes were too big and thick and that they could build their model with folded paper. Mehmet suggested using cardboard. Consequently, they found cardboard leaves and started to fold them. Tulin came up with a white sheet of paper and suggested covering the cardboard with it. They glued the paper to the cardboard together. Mehmet, Ufuk and Tulin started drawing the screen for the model. When Rutkay asked Mehmet what he was drawing, Mehmet answered by saying he was drawing a camera lens. Students discussed whether they should write "Samsung" or iPhone" on the back of their model (V1 $\left.{ }^{\mathrm{b}}, 16^{\prime} 33^{\prime \prime}\right)$.

As seen in Sample 5, students built a model device of their own choice, matching features within the Social Studies topics. Creating a product enabled them to use concepts related to the subject and offer explanations to one another during their work. They were guided by questions and answers while creating a product when they had limited experience in the subjects.

\section{Discussion}

This study focused on the CLM applications carried out in the Social Studies course at the $4^{\text {th }}$-grade level, with SHL, who received an auditory-oral approach-based education. Social Studies course, CLM applications and the auditory-oral approach display similarities in terms of students' access to and use of information as well as group work, which made the implementation of the research easier. Goals of socialization in the Social Studies course (Zarrillo, 2012), group work in CLM (Johnson \& Johnson, 2017), and experiencing information through communication skills in the auditory-oral approach (Clark, 2006) constitute the common denominators of this research.

Social Studies course involves group work aiming to prepare students for social life (Zarrillo, 2012). Throughout this study, SHL were provided with an educational environment where they could use their previous knowledge and experience, live and learn, and actively participate in the learning process in the Social Studies course and the follow-up activities. In the meantime, they participated in activities such as watching instructional videos and documentaries, examining objects/documents, preparing flyers/brochures, drawing timelines and tables, and building models and posters. Existing literature demonstrates that activities of this nature offer the students the opportunity to discuss concepts as a group and acquire information through real-life experience (Obenchain \& Morris, 2011). The materials used in the study required adapting to the age and knowledge level of the SHL so that they would support the goals of the course.

The researcher used Vitamin Interaktif Egitim Videoları approved by the Ministry of National Education in this study (http://www.vitaminegitim.com/). The fact that the videos involved an animated presentation of the subjects and the concepts attracted students' attention and helped materialize the concepts. Unfortunately, however, the knowledge and experience of SHL on the Social Studies concepts are limited. This necessitated pausing the videos at times and emphasizing the causal relationships between events. Concepts that required clarification were drawn on the board and visualized over realia and authentic documents. Knowledge of the subjects and concepts were further consolidated by recurrent use in Turkish and Mathematics lessons.

Follow-up activities of the Social Studies lessons enable gaining experience and meaningful learning by using the information learned in the lessons (Brophy \& Alleman, 2009). During the study, the students developed products as outcomes of common goals to ensure that they live and learn simultaneously. The materials helped create a product in that they led students to reflect on how they would go about creating their product and interpret the concepts.

CLM involves not only planning and collaboration but also group work with a common goal and creating a product (Johnson \& Johnson, 2017; Slavin, 2015). In order for the planning phase of CLM to be effective, it is important to set reasonable goals, and choose practical activities and materials (Zarrillo, 2012). Students in the study displayed individual differences in their understanding of the questions, expression levels and ability to establish cause-effect relationships. Therefore, the materials were chosen with care in the planning and material selection stages to provide variety in question styles and clearly illustrate the cause-effect relationships.

Individual differences between the students were taken into consideration in this study to ensure that they achieve the goals of the Social Studies course. Reasonable goals enabled students to structure meaning. The goals were set specifically to provide active participation and experience concepts. Literature states that heterogeneous group work 
reduces individual competition and increases positive interdependence (Zarrillo, 2012). A similar outcome was obtained in the students' interaction in the process of building models and discussing poster design as part of the study.

Collaboration is another one of the most important aspects of CLM. This process is reported to reinforce the fulfillment of responsibilities and positive interdependence while easing the cognitive workload of students with different characteristics through peer teaching (Dillenbourg, 1999). Students with greater individual differences also required their teacher's support in addition to their peers' to carry out their responsibilities in group work activities. It was observed that this additional support enabled these students to learn the concepts pertaining to the Social Studies course from the material, the teacher or their peers without feeling academically inferior. This finding is in line with the findings of the existing research in the literature, which demonstrated that SHL perform and focus better with CLM as compared to individual learning (Hinson, 2015).

The literature points out that SHL need CLM applications to gain new experiences (Xie, Potměšil \& Peters, 2014). In this study, the follow-up activities concerning task cards, models, and posters have enabled the students to demonstrate their learning experiences on the subjects pertaining to the Social Studies course. Students have examined objects in this course. It can be safely claimed that they integrated their knowledge and observations to gain new experiences in these follow-up activities.

Another prominent component of CLM is group work with a common goal. It has been reported that these activities allow discussions on the concepts, putting the information into use, relating new information to the existing knowledge and reasoning (Johnson \& Johnson, 2017). It was observed throughout this study that CLM enabled group discussions over the concepts learned in the Social Studies lessons. Various studies in the literature accentuate the importance of acquiring experience and oral language skills while learning concepts (Neuman, Newman \& Dwyer, 2011). The students in this study were able to participate in discussions over the concepts, thanks to the fact that they received an auditory-oral approach-based education from an early age. CLM's group work content and the principles of the auditory-oral approach concerning communication skills converge within the frame of group activities with active participation. This common feature enabled the students in this study to put the concepts into words, discuss their meaning, and use the words in different contexts. This particular finding is parallel to other research findings, which indicate that group work activities in CLM facilitate the retention of information by improving the students' skills in accessing, structuring, and presenting information (Klinger, Vaughn \& Schumm, 1998; Slavin, 1983).

A variety of materials have been used in the educational environment in this study to provide students with access to information. Students were guided with questions, explanations and visual clues to help them structure the information. Creating a product in the follow-up activities has given the students the grounds to participate in the discussions using what they have learned. Klinger, Vaughn and Schumm (1998) indicate that, with CLM, students spend a substantial amount of time discussing the academic content and that they apply communication strategies in a consistent manner. It was observed in this study also that the students could discuss academic content covered in the process of collaboration in group work activities and the process of creating a product using the communication strategies. Slavin (1983) observes that a small act of support by their CLM peers greatly contributes to the students' learning. Similarly, in this study, students with distinct individual differences were observed to benefit from their peers' explanations and thoughts. CLM is a process of creating a product, in which students collaborate within groups with a common goal (Zarrillo, 2012). The students' willingness to create products, the teacher's encouragement in the process and due preparation facilitated collaboration in this study. It could be claimed that the communication techniques of the auditory-oral approach supported the use of the concepts of the Social Studies course in the process, as well.

Stinson and Liu (1999) emphasize that the contribution of the educational environment on learning in inclusive classrooms depends on the attitude of both the teacher and the hearing students as well as the oral language skills of the student with hearing loss. It can be contended that the students who participated in this study have benefited from meaningful learning opportunities as much as their hearing peers because they had cochlear implants and had received auditory-oral education since an early age. Antia, Stinson, and Gaustad (2003) point out that CLM applications are useful in inclusive classrooms with SHL. The first stage in the discussion of Social Studies concepts and the students' creation of products in this study determined individual differences among students. The next stage was to make the students understand the concepts through the materials used, strategies developed, and the collaborative learning process. To ensure this, the teacher explained the materials thoroughly, activated previous knowledge, encouraged participation in product creation, and created a meaningful learning environment by asking 
questions that established causal relationships. It is absolutely necessary that early CLM applications and due planning of the applications in accordance with the students' individual needs be integrated into the educational programs for SHL. It requires further research to assess the learning of Social Studies course concepts of SHL using quantitative research methods and study the CLM applications after integrating the Social Studies course's subject matter to other disciplines such as Turkish and Mathematics.

\section{Conclusions}

In order for students to fully benefit from the process, it is essential to set reasonable goals and prepare suitable materials for all students with individual differences in the planning stage of CLM. For SHL who have received auditory-oral approach-based education, CLM contributes to various skills such as participating in discussions over the concepts learned, reasoning and fulfilling individual responsibilities through shared work in positive interdependence in the Social Studies course. Notwithstanding, SHL need a greater emphasis on the causal relationships between the concepts, repetition of the concepts in different contexts, strategies in the Social Studies course and more visual materials. Once these are ensured, SHL can learn the Social Studies course concepts as successfully as their hearing peers. In accordance with the findings of the current study, it can be safely claimed that CLM facilitates the development of both oral language skills and academic skills of SHL.

\section{References}

Adams, A. R. (2013). Cooperative learning effects on the classroom (Unpublished Master Thesis). USA: Northern Michigan University.

Antia S. D., Stinson, M. S., \& Gaustad M. G. (2002). Developing membership in the education of deaf and hard of hearing students in inclusive setting. Journal of Deaf Study and Deaf Education, 7(3), 214-229. https://doi.org/10.1093/deafed/7.3.214

Antia, S. D., Kreimeyer, K. H., \& Eldredge, N. (1994). Promoting social interaction between young children with hearing impairments and their peers. Exceptional Children, 60(3), 262-275. https://doi.org/10.1177/001440299406000307

Avcioglu, H. (2001). Examining the effectiveness of program development for teaching social skills to hearing impaired students based on cooperative learning (Unpublished doctoral thesis). Ankara: Ankara University.

Boons, T., Raeve, L., Langereis, M., Peeraer, L., Wouters, J., \& Wieringen, A. (2013). Narrative spoken language skills in severely hearing-impaired school-aged children with cochlear implants. Research in Developmental Disabilities, 34, 3833-3846. https://doi.org/10.1016/j.ridd.2013.07.033

Brophy, J., \& Alleman, J. (2009). Meaningful social studies for elementary students. Teachers and Teaching: Theory and Practice, 15(3), 357-376. https://doi.org/10.1080/13540600903056700

Clark, (2006). A practical guide: a quality interaction with who have a hearing loss. Plural Publishing Inc.

Dillenbourg, P. (1999). What do you mean by collaborative learning? In Dillenbourg (Ed.), Collaborative-learning: Cognitive and Computational Approaches (pp.1-19). Oxford: Elsevier.

Ducharme, D. E., \& Holborn, S. W. (1997). Programming generalization of social skills in pre-school children with hearing impairments. Journal of applied behavior analysis, 30, 639-651. https://doi.org/10.1901/jaba.1997.30-639

Hinson, T. (2015). Perspectives on cooperative learning: A case study of Kagan cooperative learning structures in the classroom (Unpublished Dissertation Thesis). East Carolina University, USA.

Gaustad, M. G. (1999). Including the kids across the hall: Collaborative instruction of hearing, deaf, and hard-of-hearing students. Journal of Deaf Studies and Deaf Education, 4(3), 176-190. https://doi.org/10.1093/deafed/4.3.176

Johnson, D. W., \& Johnson, T. (1985). Mainstreaming hearing-impaired students: The effect of effort in communicating on cooperation and interpersonal attraction. The Journal of Psychology Interdisciplinary and Applied, 119(1), 31-44. https://doi.org/10.1080/00223980.1985.9712604

Johnson, D. W., \& Johnson, R. T. (2017). Cooperative learning. Innovacion Educacion. I Congreso Interonacional. 22-23 de Septiembre, Ponencia plenaria: Zaragoza.

Johnson, D. W., Wardlow, G. W., \& Franklin, T. D. (1997). Hands-on activities versus worksheets in reinforcing 
physical science principles: Effects on student achievement and attitude. Journal of Agricultural Education, 38(3), 9-17. https://doi.org/10.5032/jae.1997.03009

Karasu, H. P., Girgin, U., \& Gurgur, H. (2015). Supporting a Hearing-Impaired Child's Literacy Development with Language Experience Approach. Turkish Online Journal of Qualitative Inquiry, 6(1), 111-144. https://doi.org/10.17569/tojqi.67264

Klinger, J. K., Vaughn, S., \& Schumm, J. S. (1998). Collaborative strategic reading during social studies in heterogeneous fourth-grade classrooms. The Elementary School Journal, 99(1), 3-21. https://doi.org/10.1086/461914

Kluwin, T. N., Stinson, M. S., \& Colarossi, G. M. (2002). Social processes and outcomes of in-school contact between deaf and hearing peers. Journal of Deaf Studies and Deaf Education, 7, 200-213. https://doi.org/10.1093/deafed/7.3.200

Korkmaz Toklucu, S., \& Tay, B. (2016). The effect of cooperative learning method and systematic teaching on students' achievement and retention of knowledge in social studies lesson. Eurasian Journal of Educational Research, 66, 315-334. https://doi.org/10.14689/ejer.2016.66.18

Kus, Z., \& Karatekin, K. (2009). The Effect of Cooperative Learning on Academic Success in Social Studies Course. Journal of Education Faculty, XXII(2), 589-604.

Leton, S. I., Wahyudin, \& Dosinaeng, W. B. D. (2019). Hearing-impaired student ability to solve the problem in math. Journal of Physics: Conference Series, $1321(2019), \quad 02211$. https://doi.org/10.1088/1742-6596/1321/2/022111

Levstik, L. S., \& Barton, K. C. (2001). Doing history: Investigating with children in elementary and middle schools (2nd ed.). Mahwah, NJ: Lawrence Erlbaum Associates. Learning to Teach History as Interpretation.

Miller, K. J. (1995). Cooperative conversations: The effect of cooperative learning on conversational interaction. American Annals of the Deaf, 140(1), 28-37. https://doi.org/10.1353/aad.2012.0299

Milli Egitim Bakanligi [MEB]. (2018). Social Studies curriculum (primary and secondary school grades 4, 5, 6 and 7). Ankara.

Neuman, S. B., Newman, E. H., \& Dwyer, J. (2011). Educational effects of a vocabulary intervention on preschoolers' word knowledge and conceptual development: A cluster-randomized trial. Reading Research Quarterly, 46(3), 249-272.

Obenchain, K. M., \& Morris, R. V. (2011). 50 social studies strategies for K-8 classrooms (3rd ed.). Boston: Pearson.

Pimperton, H., \& Kennedy, C. R. (2012). The impact of early identification of permanent childhood hearing impairment on speech and language outcomes. Global Child Health, 97, 648-653. https://doi.org/10.1136/archdischild-2011-301501

Reilly, N., \& Khanh (2004). Inclusive education for hearing-impaired and deaf children in Vietnam. Pearl S. Buck International/Vietnam Final Evaluation Report.

Remmen \& Frøyland (2015). What happens in classrooms after earth science fieldwork? Supporting student learning processes during follow-up activities. International Research in Geographical and Environmental Education, 24(1), 24-42. https://doi.org/10.1080/10382046.2014.967114

Scheuerell, S. (2010). Virtual Warrensburg: Using cooperative learning and the Internet in the social studies classroom. The Social Studies, 101(5), 194-199. https://doi.org/10.1080/00377990903493861

Slavin, R. E. (2015). Cooperative learning in elementary schools. Education 3-13, 43(1), 5-14. https://doi.org/10.1080/03004279.2015.963370

Slavin, R. E. (1983). When does cooperative learning increase achievement? Psychological Bulletin, 94(3), 429-445. https://doi.org/10.1037/0033-2909.94.3.429

Stinson, M. S., \& Liu, Y. (1999). Participation of deaf and hard-of-hearing students in classes with hearing students. Journal of Deaf Studies and Deaf Education, 4(3), 191-202. https://doi.org/10.1093/deafed/4.3.191

Xie, Y., Potměšil, M., \& Peters, B. (2014). Children who are deaf or hard of hearing in inclusive educational settings: A literature review on interactions with peers. Journal of Deaf Studies and Deaf Education. 19(4), 423-437. https://doi.org/10.1093/deafed/enu017 
Yin, K. R. (2014). Case study research: Design and methods (5th ed.). Los Angeles: Sage.

Zarrillo, J. J. (2012). Teaching Elementary Social Studies: Principles and Applications (4th ed.). Upper Saddle River, NJ: Pearson.

\section{Copyrights}

Copyright for this article is retained by the author(s), with first publication rights granted to the journal.

This is an open-access article distributed under the terms and conditions of the Creative Commons Attribution license (http://creativecommons.org/licenses/by/4.0/). 